\title{
Effect of microstructure on the high temperature strength of nitride bonded silicon carbide composite
}

\author{
J RAKSHIT and P K DAS* \\ Central Glass and Ceramic Research Institute, Kolkata 700 032, India
}

MS received 15 March 2002; revised 3 August 2002

\begin{abstract}
Four compositions of nitride bonded $\mathrm{SiC}$ were fabricated with varying particle size of $\mathrm{SiC}$ of $\sim 9.67, \sim 13.79, \sim 60 \mu$ and their mixture with $\mathrm{Si}$ of $\sim 4.83 \mu$ particle size. The green density and hence the open porosity of the shapes were varied between 1.83 to $2.09 \mathrm{~g} / \mathrm{cc}$ and 33.3 to $26.8 \mathrm{vol} \%$, respectively. The effect of these parameters on room temperature and high temperature strength of the composite up to $1300^{\circ} \mathrm{C}$ in ambient condition were studied. The high temperature flexural strength of the composite of all compositions increased at 1200 and $1300^{\circ} \mathrm{C}$ because of oxidation of $\mathrm{Si}_{3} \mathrm{~N}_{4}$ phase and blunting crack front. Formation of $\mathrm{Si}_{3} \mathrm{~N}_{4}$ whisker was also observed. The strength of the mixture composition was maximum.
\end{abstract}

Keywords. Nitride bonded silicon carbide composite; nitridation; microstructure.

\section{Introduction}

Nitride bonded silicon carbide (NBSC) composite is a promising high temperature refractory material for its high strength at high temperature, good fracture toughness, excellent thermal shock and oxidation resistances (Reddy and Mukerji 1991). As SiC has a tendency for oxidation to occur in service at high temperature, a silicon nitride bond offers protection to $\mathrm{SiC}$ grains by preferentially oxidizing to silica which also reduces the porosity (Davidge et al 1972; Pick 1979). Among the various fabrication techniques, reaction bonding process has been found attractive because of its near net shaping capability (Chiang et al 1989) and reduced cost of production because of low processing temperature (Rakshit and Das 1996). Compositing of SiC (whisker or particulate) with silicon nitride in a dense product was found to improve both fracture toughness and flexural strength (up to $1400^{\circ} \mathrm{C}$ ) compared to dense monolithic $\mathrm{Si}_{3} \mathrm{~N}_{4}$ (Buljan et al 1987; Pizzotti et al 1989). The extensive use of nitride bonded silicon carbide refractory in the area of (i) iron and steel industry, (ii) non ferrous industry, (iii) kiln furniture, (iv) coal fired power plants etc are well known.

The present work includes study of the effect of microstructure and possible existence of silica (cristobalite) in the matrix (after hot MOR) on the strength improvement at high temperature.

\section{Experimental}

Commercial grade $\mathrm{Si}$ powder $(97.5 \%$ purity, obtained from Indian Metals and Ferroalloys, Bhubaneswar, India) of mean particle size $\sim 4.83 \mu$ and $\mathrm{SiC}$ powder $(98 \%$

\footnotetext{
*Author for correspondence
}

purity from Grindwell Norton, India) of three varieties having average particle sizes of $\sim 9.67 \mu, \sim 13.79 \mu$ and $\sim 60 \mu$ (considered as fine, medium and coarse varieties, respectively) were selected in this study. Each variety of powder and one batch containing appropriate mixture (fine : medium : coarse $=30: 35: 35$ by weight) of the three were mixed with fixed amount of $\mathrm{Si}$ powder $(100: 30 \mathrm{w} / \mathrm{w})$ separately and wet blended in a "V" mixer for $6 \mathrm{~h}$. Test bars were made by uniaxial pressing at $23.5 \mathrm{MPa}$ to a small rectangular shape of $45 \times 6 \times$ $5 \mathrm{~mm}$ size. The test bars were reacted with high purity nitrogen gas $\left(\mathrm{O}_{2}\right.$ and $\mathrm{H}_{2} \mathrm{O}$ vapour, $\sim 4 \mathrm{ppm}$ each, oxides of carbon, $\sim 1 \mathrm{ppm}$ ) at $1 \mathrm{~atm}$ pressure. The details of preparative method followed was similar to those given earlier (Reddy and Mukerji 1991; Rakshit and Das 1996); bulk density and open porosity of the nitrided samples were determined by water immersion process. Mean pore diameter $\left(d_{50}\right)$ was determined from cumulative pore size distribution by mercury intrusion porosimeter (Quantachrome, Model No. Autoscan 60, USA). Existence of phases $\left(\alpha-, \beta-\mathrm{Si}_{3} \mathrm{~N}_{4}, \mathrm{SiO}_{2}\right.$, etc) were determined by XRD technique. Both room temperature and high temperature MOR were determined by 4-point loading in a bending strength tester (Netzsch, Model No. 422 S, Type B-3, Germany) using fixture with larger and smaller span of $40 \mathrm{~mm}$ and $20 \mathrm{~mm}$ and cross head speed of $0.03 \mathrm{~mm} / \mathrm{sec}$. At least 5 samples were tested in each case. Microstructure was observed on fractured surface of both RT and HT piece in an electron microscope (Leo Cambridge, SE 440, UK).

\section{Results and discussion}

Table 1 shows the results of four different batches of nitride bonded $\mathrm{SiC}$ (NBSC) in respect of density, 
Table 1. Properties of nitride bonded $\mathrm{SiC}$ composite materials.

\begin{tabular}{|c|c|c|c|c|c|c|c|}
\hline \multirow[b]{2}{*}{ Sample } & \multicolumn{2}{|c|}{ Density $\left(\mathrm{g} / \mathrm{cm}^{3}\right)$} & \multirow{2}{*}{$\begin{array}{l}\text { Open porosity } \\
\quad(\text { vol. } \%)\end{array}$} & \multirow{2}{*}{$\begin{array}{c}\text { Mean pore } \\
\text { dia. }\left(d_{50 \mu}\right)\end{array}$} & \multicolumn{3}{|c|}{$\operatorname{MOR}(\mathrm{MPa})$} \\
\hline & Green & Nitrided & & & RT & $1200^{\circ} \mathrm{C}$ & $1300^{\circ} \mathrm{C}$ \\
\hline$C_{1}$ & 1.83 & $2 \cdot 10$ & $33 \cdot 3$ & $0 \cdot 36$ & $31.9 \pm 4.9$ & $59 \cdot 4 \pm 5 \cdot 1$ & $68.9 \pm 2.4$ \\
\hline$C_{2}$ & 1.90 & $2 \cdot 20$ & $30 \cdot 4$ & $0 \cdot 27$ & $41 \cdot 4 \pm 5 \cdot 3$ & $71 \cdot 9 \pm 14.5$ & $79 \cdot 3 \pm 13 \cdot 6$ \\
\hline$C_{3}$ & $2 \cdot 09$ & $2 \cdot 33$ & $26 \cdot 8$ & 0.52 & $26 \cdot 4 \pm 7 \cdot 2$ & $56 \cdot 9 \pm 6 \cdot 0$ & $64 \cdot 0 \pm 12 \cdot 4$ \\
\hline$C_{4}$ & $2 \cdot 04$ & $2 \cdot 25$ & $28 \cdot 5$ & 0.21 & $46 \cdot 5 \pm 6 \cdot 4$ & $70 \cdot 2 \pm 9 \cdot 4$ & $90 \cdot 5 \pm 1.9$ \\
\hline$S_{1}$ & $1 \cdot 20$ & $2 \cdot 21$ & $23 \cdot 3$ & - & $88.7 \pm 8.6$ & $118 \cdot 0 \pm 4 \cdot 4$ & $116 \cdot 6 \pm 11 \cdot 0 *$ \\
\hline$S_{2}$ & $1 \cdot 37$ & $2 \cdot 39$ & $18 \cdot 0$ & - & $122 \cdot 1 \pm 12 \cdot 5$ & $153 \cdot 7 \pm 19 \cdot 1$ & $131.8 \pm 16.9 *$ \\
\hline$S_{3}$ & 1.43 & $2 \cdot 44$ & $16 \cdot 2$ & - & $135 \cdot 0 \pm 4 \cdot 4$ & $166 \cdot 4 \pm 22 \cdot 8$ & $147 \cdot 1 \pm 13 \cdot 2 *$ \\
\hline
\end{tabular}

$C_{1} \rightarrow \mathrm{Si}+$ fine $\mathrm{SiC}, C_{2} \rightarrow \mathrm{Si}+$ medium $\mathrm{SiC}, C_{3} \rightarrow \mathrm{Si}+$ coarse $\mathrm{SiC}, C_{4} \rightarrow \mathrm{Si}+\operatorname{mix} \mathrm{SiC}$.

$S_{1}, S_{2}, S_{3} \rightarrow$ RBSN samples of same dimension as NBSC samples. Green shapes were made by uniaxial pressing at 23-31 MPa. *Strength measured at $1400^{\circ} \mathrm{C}$.

porosity, average pore diameter $\left(d_{50}\right)$ and flexural strength both at room temperature (RT) and high temperatures (HT).

Since the bonding phase, $\mathrm{Si}_{3} \mathrm{~N}_{4}$, is almost fixed (32 wt\%) in each batch, the bulk density of the composites increases and open porosity (vol.\%) decreases as the green density increases. In composite $C_{3}$, containing coarse variety of $\mathrm{SiC}$, mean pore diameter $\left(d_{50}\right)$ is the largest among the other batch compositions, which is least $\left(d_{50}=0.21 \mu \mathrm{m}\right)$ in $C_{4}$ containing a mixture of fine, medium and coarse varieties of $\mathrm{SiC}$ particles although the open porosity is least $(26.8 \%)$ in the former case. Therefore, batch composition containing multimodal particle packing would result in material with maximum number of fine pores as explained in the earlier work (Rakshit and Das 1996). Figure 1 shows the XRD patterns of composite $\left(C_{4}\right)$ material showing the existence of exclusively $\alpha \mathrm{Si}_{3} \mathrm{~N}_{4}$ with a little amount of $\beta-\mathrm{Si}_{3} \mathrm{~N}_{4}$ as nitridation product instead of major $\mathrm{SiC}$ phase. The absence of $\mathrm{Si}$ indicates that nitridation is completed. Figure 2 is the XRD pattern of the same material $\left(C_{4}\right)$ after MOR tested at $1300^{\circ} \mathrm{C}$. The results are almost identical, only difference is in the existence of silica (cristobalite) and silicon oxynitride in the latter case. This is due to oxidation of nitride bonded $\mathrm{SiC}$ composite preferentially at $\mathrm{Si}_{3} \mathrm{~N}_{4}$ grains in the matrix.

A low value of MOR at room temperature of $C_{3}$ containing coarse variety of $\mathrm{SiC}$ particle and high room temperature MOR value of $C_{4}$ containing mixture of $\mathrm{SiC}$ particles are attributed to porosity and pore size distribution of the materials in general agreement with our results reported earlier (Rakshit and Das 1996).

Flexural strength of all composites in ambient condition shows an increasing trend with increase of temperature up to $1200^{\circ} \mathrm{C}$ (figure 3), similar to uniaxially pressed and nitrided reaction bonded silicon nitride (Mukerji and Rakshit 1988) and a sharp increase above $1200^{\circ} \mathrm{C}$. Strength improvement is maximum (at $1300^{\circ} \mathrm{C}$ ) in case of $C_{4}$ containing mixture of $\mathrm{SiC}$ particles. Unlike reaction bonded

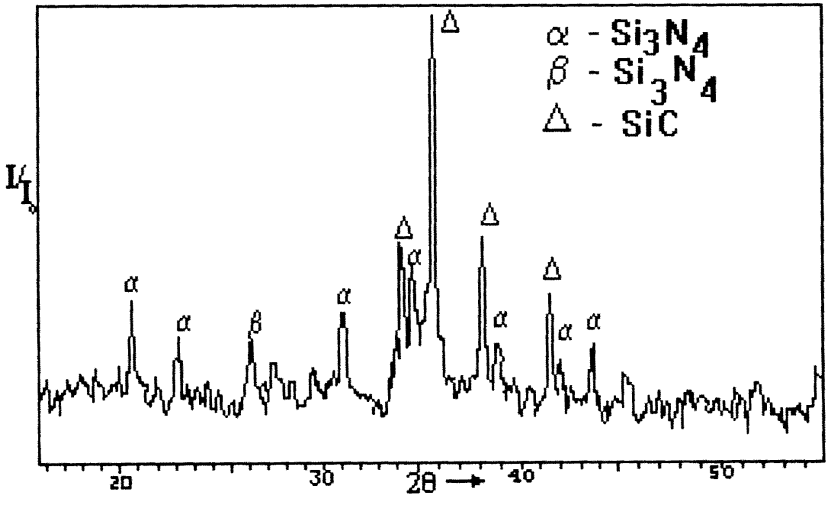

Figure 1. XRD pattern of nitride bonded silicon carbide (NBSC) material $\left(C_{4}\right)$, containing $\mathrm{Si}+\mathrm{SiC}$ mixture.

silicon nitride, in which a strength degradation was observed above $1200^{\circ} \mathrm{C}$ (table 1) [because of viscous flow of the grain boundary vitreous silica layer formed due to oxidation of $\mathrm{Si}_{3} \mathrm{~N}_{4}$ phase (Mukerji and Rakshit 1988)], no such degradation was observed in NBSC samples. Previous study on nitride bonded $\mathrm{SiC}$ (Mukerji 1984) where $\mathrm{SiC}$ was the predominant phase $(80 \%)$ revealed the strength to increase continuously up to $1400^{\circ} \mathrm{C}$. A number of inferences were made by different workers for improved strength of NBSC materials at elevated temperatures. Increase of strength with temperature (up to $1200^{\circ} \mathrm{C}$ ) was accepted to be a result of oxidation and crack healing due to oxidation at the crack tip (Mukerji and Rakshit 1988). Further increase of MOR above $1200^{\circ} \mathrm{C}$ is attributed to the presence of $\mathrm{Si}_{2} \mathrm{~N}_{2} \mathrm{O}$ on the surface of $\mathrm{Si}_{3} \mathrm{~N}_{4}$ grains (Mukerji and Rakshit 1988). Others (Mukerji and Reddy 1980) explained the case with the help of microstructure. According to them, whisker and woolly felt of $\alpha-\mathrm{Si}_{3} \mathrm{~N}_{4}$ was converted into a consolidated hard intergranular phase of $\alpha-\mathrm{Si}_{3} \mathrm{~N}_{4}$ when the product was under load at high temperature thereby resulting in an increase in strength. 


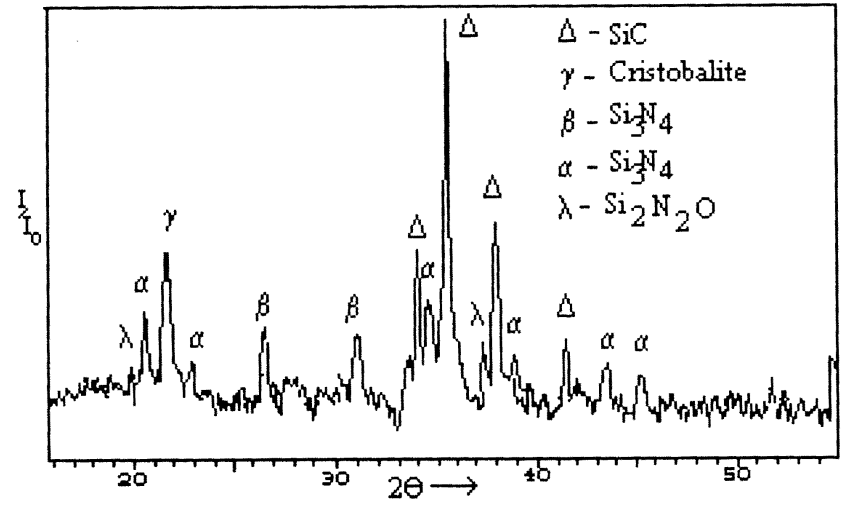

Figure 2. XRD pattern of nitride bonded silicon carbide (NBSC) material $\left(C_{4}\right)$, containing $\mathrm{Si}+\mathrm{SiC}$ mixture, after hot MOR at $1300^{\circ} \mathrm{C}$.

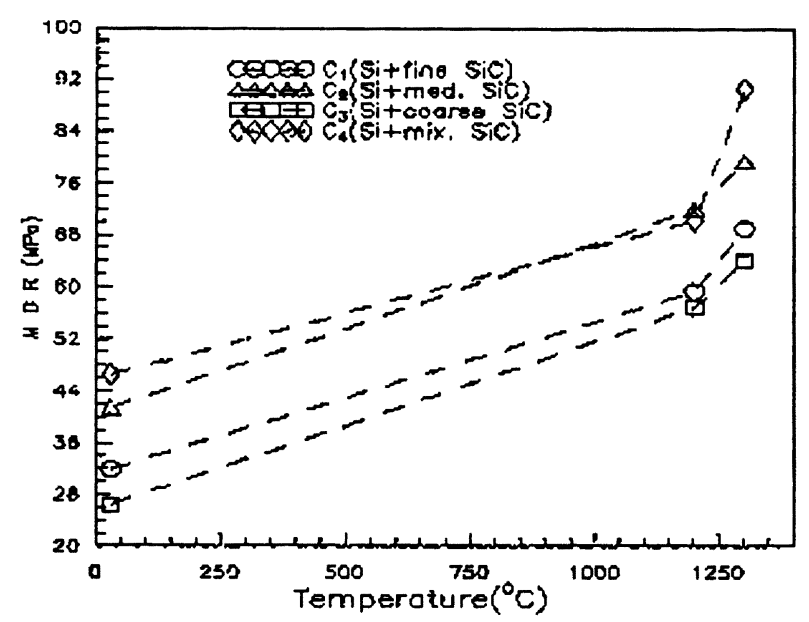

Figure 3. Dependence of MOR of NBSC materials (32 wt $\%$ nitride bond) with temperature.

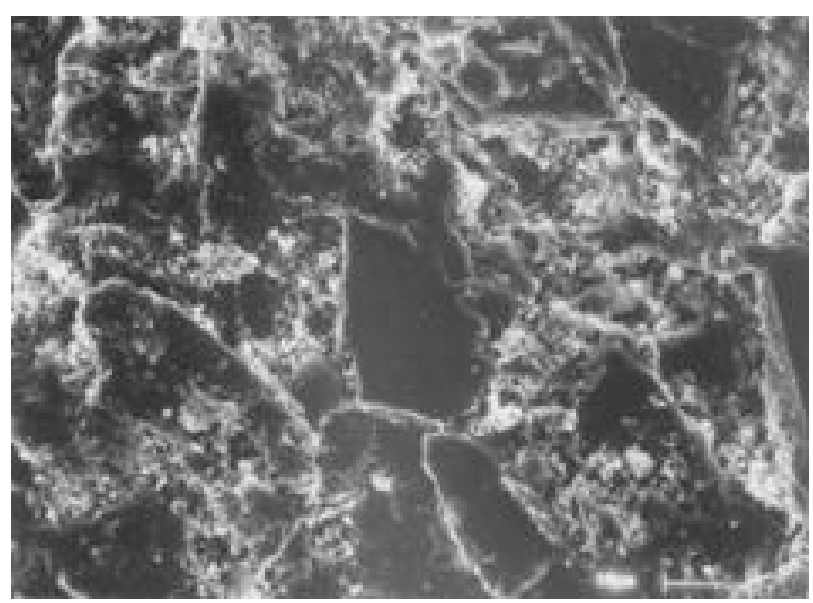

Figure 4. SEM photomicrograph of fractured surface of nitride bonded silicon carbide (NBSC) material $\left(C_{4}\right)$ showing light grey boundaries of $\mathrm{Si}_{3} \mathrm{~N}_{4}$ around large $\mathrm{SiC}$ grains (bar = $10 \mu \mathrm{m})$.
Scanning electron micrograph (SEM) of the fractured surface of the composite $\left(C_{4}\right)$ containing mixture of $\mathrm{SiC}$ particles both at room temperature and at high temperature $\left(1300^{\circ} \mathrm{C}\right)$ are shown in figures $4-6$, respectively. In figure $4, \mathrm{Si}_{3} \mathrm{~N}_{4}$ bond appears as light grey boundaries around large $\mathrm{SiC}$ (deep grey) grain. No pullout of silicon nitride was observed, which indicates strong bonding between $\mathrm{SiC}$ and newly formed $\mathrm{Si}_{3} \mathrm{~N}_{4}$ grains. Figure 5 shows the formation of needle like whiskers of $\alpha \mathrm{Si}_{3} \mathrm{~N}_{4}$ into the large pores by the side of large $\mathrm{SiC}$ grains. Unreacted $\mathrm{Si}$ could not be seen in the micrograph. At high temperature $\left(1300^{\circ} \mathrm{C}\right)$, no such wool or whisker is observed (figure 6). They have been converted into consolidated grains of $\alpha \mathrm{Si}_{3} \mathrm{~N}_{4}$ with a glassy (cristobalite) phase in between large $\mathrm{SiC}$ grains. The pores of oxidized material is rounded off by formation of silica reducing

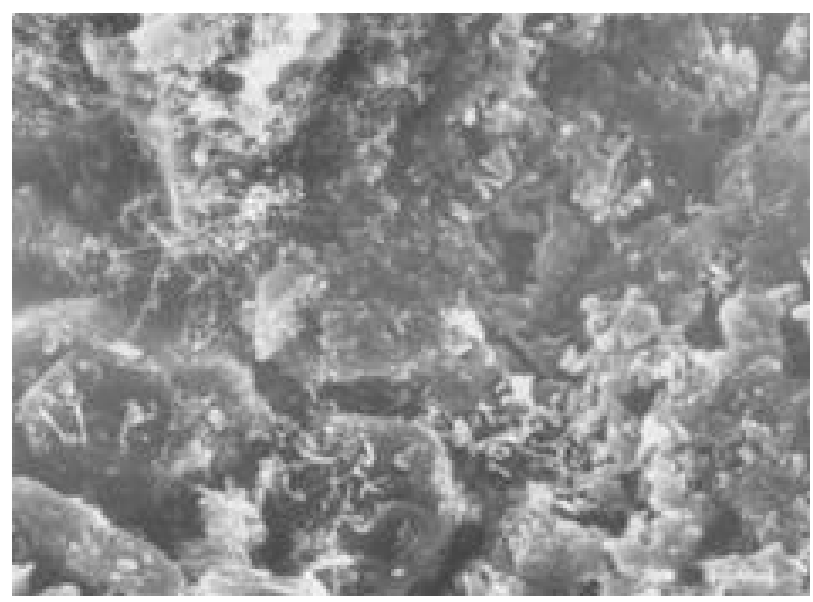

Figure 5. SEM photomicrograph of fractured surface of NBSC material $\left(C_{4}\right)$ showing needle like whiskers in large pores $($ bar $=2 \mu \mathrm{m})$.

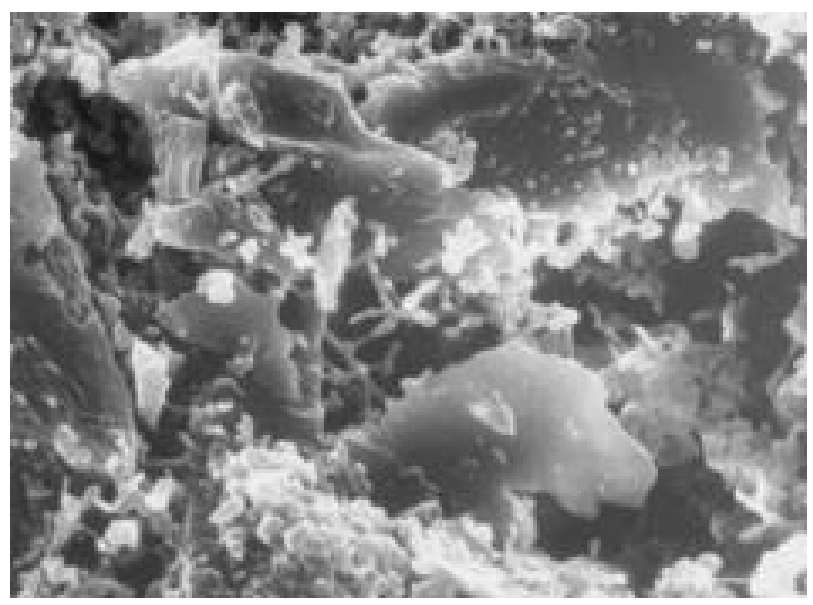

Figure 6. SEM photomicrograph of fractured surface of NBSC material $\left(C_{4}\right)$ after MOR testing at $1300^{\circ} \mathrm{C}$ showing glassy phase of cristobalite in between large $\mathrm{SiC}$ grains (bar = $2 \mu \mathrm{m}$ ). 
the pore size of the original sample (figure 6), as a result of which the material showed high flexural strength at hot condition (Davidge et al 1972). The existence of $\mathrm{Si}_{2} \mathrm{~N}_{2} \mathrm{O}$ as detected by XRD, could not be identified in the microstructure (figure 6). The formation of silicon oxynitride during oxidation reduces microstructural degradation of composite materials and could have an influence on improved mechanical property at high temperature similar to dense composite $\left(\mathrm{Si}_{3} \mathrm{~N}_{4}-\mathrm{SiC}\right.$ ) materials (Klemm et al 1997).

\section{Conclusions}

(I) Batch composition containing mixed $\mathrm{SiC}$ particle packing would result in a material with maximum number of fine pores.

(II) Low value of room temperature MOR is due to presence of large pores and not the total vol.\% (open) porosity of the composite.

(III) Flexural strength of all composites in ambient condition showed an increasing trend with increase of temperature up to $1300^{\circ} \mathrm{C}$. Oxidation and crack healing at the crack tip and also the existence of $\mathrm{Si}_{2} \mathrm{~N}_{2} \mathrm{O}$ phase on the surface of $\mathrm{Si}_{3} \mathrm{~N}_{4}$ grains could be the cause of strength improvement at high temperature.

(IV) Needle like whisker of $\alpha \mathrm{Si}_{3} \mathrm{~N}_{4}$ is converted into a consolidated grain of $\alpha \mathrm{Si}_{3} \mathrm{~N}_{4}$ at high temperature $\left(1300^{\circ} \mathrm{C}\right)$ along with the presence of a glassy (cristobalite) phase in between large $\mathrm{SiC}$ grains.

\section{Acknowledgements}

The authors are grateful to the Director for his interest in the work. Thanks are also rendered to the staff members of Non Oxide Ceramic Section, X-ray Section and Electron Microscopy Section for their help.

\section{References}

Buljan S T, Baldoni J G and Hukabee M L 1987 Am. Ceram. Soc. Bull. 66347

Chiang Y, Haggerty T S, Messner R P and Demerty C 1989 Am. Ceram. Soc. Bull. 68420

Davidge R W, Evans A G, Gilling D and Wilyman P R 1972 Spl ceram. (ed.) P Popper (Stroke-on-Trent: Br. Ceram. Res. Assoc.) 5 p. 3239

Klemm H, Herrmann M and Schubert C 1997 Ceram. Engg. Sci. Proc. 18615

Mukerji J 1984 Trans. Indian Refrac. Makers Assoc. 173

Mukerji J and Rakshit J 1988 Ceram. Int. 141461

Mukerji J and Reddy N K 1980 J. Indian Refrac. Makers Assoc. 1310

Pick A N 1979 Trans. J. Br. Ceram. Soc. 7813

Pizzotti G et al 1989 J. Am. Ceram. Soc. 721461

Rakshit J and Das P K 1996 Tech papers of 60th annual session of Indian Ceram. Soc., Ranchi v. 22

Reddy N K and Mukerji J 1991 J. Am. Ceram. Soc. 741139 